The proposal to set up regional health councils will be welcomed so far as they go, subject to a closer look at their suggested functions and constitution. Apart from the integration of the personal health services at local level, another fruitful development in medicine will be the growth of postgraduate medical education and all that goes with it. The organization of this together with the overall planning of the hospital and specialist services and other matters are functions suitable for regional councils, and this was recognized when some such bodies were called for as the top tier of a two-tier administrative structure. It is to be regretted therefore that the functions of the regional councils will be largely advisory, and they will not, as a proper second tier of a two-tier structure should, assume some of the larger functions that the area health authorities are too small to undertake. Some of these functions are to be assumed by the central Department. In fact, the whole picture is one of increased central control with strengthened regional offices of the Health Departmentsmaller Elephants in the periphery. To assist him "in exercising these enlarged functions" the Secretary of State will consult a new central advisory council on all matters of importance to the Health Service, "including the deployment of available resources." Its membership is to be widely drawn from within and outside the professions. In an administration structure in which the power of the centre is to be markedly increased, the composition and functions of this central advisory council will be a matter of great importance, as, indeed, will be the arrangements for professional advisory committees throughout the service.

Except for the proposed administrative structure and its relationship to local authorities, the new Green Paper, like the last one, is open for discussion. Matters yet to be worked out in detail are the functions and constitution of regional health councils, the arrangements between the area health authorities and the local authorities for sharing or exchanging services (but not which services shall belong to which authority), and the functions of the district committees. The B.M.A. last year ${ }^{5}$ agreed on several "major points of principle" which should govern any changes in the administration of the N.H.S., and the Representative Body will turn to these in examining the new proposals. Despite the firm statement that the Health Service will not be administered by local government, it will not escape the Representative Body's notice that, in making the area health authority boundaries coincide with those of the new unitary authorities and metropolitan districts, the Government has set the stage for a merger at any time in the future. The public health doctors as well as others will look closely at Mr. Crossman's severance of the personal social services into those where the primary skill needed is that of the health professions and those in which the primary need is for social care or support. The first will go to the area health authorities and the second will remain with the local authorities. Having exercised what he must think is the wisdom of Solomon in such a controversial matter, Mr. Crossman will probably need a lot of persuading to make him change his mind on it. General practitioners will welcome the recognition of their independent contractor status by the provision of statutory committees for the family practitioner services, but it will seem to other doctors that they have been unfairly

\footnotetext{
1 The Future Structure of the National Health Service, Department of Health and Social Security, 1969. London, H.M.S.O. 5s. net.

British Medical fournal, 1969, 1, 590.

3 Royal Commission on Local Government in England, 1966-9, Volume I, Report, Cmnd. 4040. London, H.M.S.O., 1969.

4 Reform of Local Government in England, February 1970. Cmnd. 4276. London, H.M.S.O.

5 British Medical fournal Supplement, 1969, 1, 55.
}

excluded from a similar provision.

Probably the Government intends to bring out a White Paper on the administration of the N.H.S. after a short interval has been given for discussion on the Green Paper. In the next few months doctors will have their hands and minds full of contentious medico-political matters closely affecting their future. The proposal for an annual retaining fee for registration with the General Medical Council was considered at a Special Representative Meeting this week after this journal went to press. The important subject of medical educational reforms and all that flows from the Todd report have yet to be debated. "Consultation" when matters for consultation pile up like this puts a strain on democracy and devalues the worth of the consultations. Nevertheless, from the opinions they have already formed from previous discussions on the administration of the Health Service doctors should be ready with informed comment on the Green Paper fairly quickly, especially since the comment may be expected to be critical.

\section{Complaints in Hospital}

Last week the Secretary of State for Scotland accepted the recommendations of a working party on the introduction of a procedure by which patients can make complaints in hospitals. The working party had been set up in 1966 as a result of another report-from the Scottish Health Services Council. ${ }^{1}$ The present report ${ }^{2}$ comes from a committee comprising 13 members, of whom three were medical men and two nurses. At the same time it has become known from leaks in the daily press that a document with similar aims for the hospitals of England and Wales is now being studied confidentially by representatives of the profession. Letters on it appear in our correspondence columns this week (page 427).

That legitimate grounds for complaints can arise in the hospital service is accepted. The difficulty is to devise a procedure which will allow their full and fair investigation but which does not at the same time encourage the laying of trivial, frivolous, or malicious charges against people-mainly doctors and nurses-who are only too keenly aware that neither their employing authority nor the Secretary of State is likely to stick up for them. The working party evidently realized how people working in the health service are likely to see the matter, for its report throughout plays down the word "complaint" and speaks much more often of "comment." The fact is, though, that a formal procedure of the kind proposed would be a considerable bureaucratic edifice, and if it was to concern itself with all the many comments that might well be set hastening through its corridors it would be a waste of time and money. But regarded as a system of dealing with genuine complaints it deserves closer examination.

In the first place the report suggests that whatever procedure may be used for looking into complaints it should be reasonably uniform in all hospitals. A complaint, or "comment," from an inpatient should go in the first instance to the ward sister, who should discuss it with the patient. At her discretion she should next inform the consultant in charge. At this stage too the sister should decide whether to record the complaint in a special "comments book," but the patient has the right to insist on its being recorded if the sister demurs. If the matter remains unresolved, or if it is a serious complaint, a written report should go either from the patient or the sister, or perhaps both, to a nominated recipient of complaints. This person, the report recommends, should be one specified 
senior officer in the hospital or group. The term "officer," which to medical men still has an odd ring to it, may denote a medical or a lay person: he might be the medical superintendent, or the group secretary, or the hospital secretary. He will take legal advice if necessary, investigate the complaint, and, if the patient remains dissatisfied, report it to the hospital board. The information booklet often sent to a patient before he goes into hospital will have an "appropriate paragraph" to explain the procedure to him, and outpatients will have it drawn to their attention on the back of the appointment card and by notices in the departments.

In the past few years reports of several deplorable episodes in hospitals have shocked everyone who has read them, and more numerous but lesser cases of conduct falling below the best standards doubtless go unreported. Partly because of this there are rumours in political circles of the appointment of a special ombudsman for the health service, or even a bevy of them to serve different regions of the country. The creation of machinery to hear complaints within the service is part of the same governmental response to pressure from the publicthat is, in the last resort, voters. Politicians should remember that the prompt, fair, and thorough investigation of a complaint is an obligation that every professional person accepts as part of his work. The sister in charge of the ward, the doctor in charge of the patient, and the matron and hospital superintendent are already regarded as the normal recipients of complaints, and seldom have any abused their trust.

These disastrous episodes must be seen in the context of our hospitals as they are today. A high proportion are antiquated, nineteenth-century buildings where the staff who work in them simply have to make the best of conditions in which any modern industrialist or shop steward would throw up his hands in despair. In some areas staff is seriously short. Many of the resident doctors and nurses who work devotedly in these places are from overseas and therefore sometimes puzzled by the language or customs of the patients in their care. Time and again the real failure when disaster has struck has been shown to stem from the impossible conditions in which professional people are expected to care for patients. Until the root causes of inefficient service are corrected, the setting up of a publicized and elaborate complaints machinery can be little more than a placebo for the public and a source of irritation and anxiety to doctors and nurses in the hospital service. Though the Scottish report emphasizes that any steps taken to protect the patients' interests should not place an unreasonable burden on hospital staff or harm their interests, its proposals seem likely to arouse misgivings.

\section{Geography of Primary Liver Cancer}

The incidence of primary liver cancer differs widely throughout the world. ${ }^{1}$ If the rate among males is used as an index the world may be divided into three main groups. In group 1 the rates are over 5 per 100,000 population. Countries with these high rates include Angola, South Africa, Nigeria, Uganda, Singapore, and Hawaii. The high rates in Singapore and Hawaii depend on the high Chinese and Japanese populations living in these areas. Group 2, comprises a few areas

\footnotetext{
1 Administrative Practice of Hospital Boards in Scotland, Scottish Health Services Council. Edinburgh, H.M.S.O. 1966

2 Suggestions and Complaints in Hospitals, Scottish Home and Health Department. Edinburgh H.M.S.O. 1969.
}

with an intermediate rate between 5 and 3.1. It includes Japan and Denmark. Countries in group 3 have a rate of 3.0 or less and contain the Americas, Europe (including Great Britain), Australia, and Northern India.

Wide gaps in our knowledge remain because information from many countries is scanty or non-existent. Moreover, figures from some underdeveloped countries may be based on reports from only one region, often an area where a medical school is situated. The Nigerian figures, for instance, are based on Ibadan, the Uganda ones on Makerere. Though knowledge is increasing, little may be known of such countries as a whole. Again statistics are often based on information from death certificates or necropsies, and where neither is forthcoming no figures are available. But much is being done by the International Agency for Research on Cancer, under the directorship of Dr. John Higginson and situated at Lyons in France, to make good the geographic differences in the reporting of cancer. This organization recently sponsored a conference on liver cancer in London, and among the conclusions was the great need for further world-wide studies of the incidence of the disease and its relationship to the general environment of the various populations at risk.

Primary liver cancers from all over the world seem to have a common histology. Bizarre columns of anaplastic cells, caricatures of normal liver cells, surround blood spaces simulating the normal hepatic sinusoids. The histology of the tumour cannot be related to the patient's country or to other diseases with which it may be associated. It does seem, however, that the tumours found at necropsy in Africans are much larger than those in Caucasians reported from Johannesburg, Cape Town, and Los Angeles. ${ }^{23}$ The association with cirrhosis also differs, being closer for tumours reported from Europe and North America than from Africa. ${ }^{4}$ Some of the differences may be due to different criteria for the diagnosis of cirrhosis. Where the cirrhosis is macronodular, a diagnosis may be possible only at necropsy and not in a small-needle biopsy specimen. ${ }^{5}$ If the necropsy rate is low and only needle biopsy is done, the numbers of patients with primary liver cancer developing in a cirrhotic liver may be underestimated.

The clinical picture also differs in different parts of the world. In the West primary liver cancer is a disease of older people, often men and especially those with established cirrhosis. In Africa younger people are affected, the disease is more acute, often simulating liver abscess, the course is shorter, and evidence of previous cirrhosis absent. ${ }^{3}$

The geographical differences are reflected in the different proportions of patients having $\alpha_{1}$-feto-protein in the serum. This fetal protein is a normal component of the serum proteins of the human fetus older than 6 weeks. ${ }^{67}$ It reaches a maximal concentration between 12 and 16 weeks of fetal life, and within a few weeks of birth it disappears from the circulation and is then absent from the serum of normal children and adults. It can be easily detected by a semiquantitative Ouchterlony immunodiffusion method. Apart from its association with a few embryonal tumours its presence in serum is specific for primary liver cell cancer. ${ }^{89}$ But its occurrence with primary liver tumours greatly differs in sera from various parts of the world. In Africa the percentage of sera containing this fetal protein is high. In West Africa, for instance, $79 \%$ of 81 patients were positive, ${ }^{10}$ and in South Africa sera from $74 \%$ of 130 Bantu patients with primary liver cancer gave positive results. ${ }^{11}$ But in Uganda the incidence was lower, the fetal protein being found only in $50 \%$ of patients with primary liver 